\title{
Upper Airway Dynamic Responses in Children with the Obstructive Sleep Apnea Syndrome
}

\author{
CAROLE L. MARCUS, ELIOT S. KATZ, JANITA LUTZ, CHERYL A. BLACK, \\ PATRICIA GALSTER, AND KATHRYN A. CARSON \\ Eudowood Division of Pediatric Respiratory Sciences [C.L.M., E.S.K., J.L., C.A.B., P.G.], Department of \\ Epidemiology [K.A.C.], Johns Hopkins University, Baltimore, Maryland, 21287
}

\begin{tabular}{|c|c|}
\hline \multicolumn{2}{|c|}{ ABSTRACT } \\
\hline $\begin{array}{l}\text { Normal children have a smaller upper airway than adults, but, } \\
\text { nevertheless, snore less and have less apnea. We have previously } \\
\text { shown that normal children have an upper airway that is resistant } \\
\text { to collapse during sleep. We hypothesized that this resistance to } \\
\text { collapse is due to preservation of upper airway neuromotor } \\
\text { responses during sleep. Furthermore, we hypothesized that upper } \\
\text { airway responses would be diminished in children with the } \\
\text { obstructive sleep apnea syndrome (OSAS). We therefore com- } \\
\text { pared the upper airway pressure-flow relationship during sleep } \\
\text { between children with OSAS and controls. Measurements were } \\
\text { made by correlating maximal inspiratory airflow with the level of } \\
\text { nasal pressure applied via a mask. Neuromotor upper airway } \\
\text { activation was assessed by evaluating the upper airway response } \\
\text { to 1) hypercapnia and 2) intermittent, acute negative pressure. } \\
\text { We found that children with OSAS had no significant response to } \\
\text { either hypercapnia or negative pressure during sleep, compared } \\
\text { with the normal children. After treatment of OSAS by tonsillec- } \\
\text { tomy and adenoidectomy, there was a trend for normalization of } \\
\text { upper airway responses. We conclude that upper airway dynamic }\end{array}$ & $\begin{array}{l}\text { responses are decreased in children with OSAS but recover after } \\
\text { treatment. We speculate that the pharyngeal airway neuromotor } \\
\text { responses present in normal children are a compensatory re- } \\
\text { sponse for a relatively narrow upper airway. Further, we specu- } \\
\text { late that this compensatory response is lacking in children with } \\
\text { OSAS, most likely due to either habituation to chronic respira- } \\
\text { tory abnormalities during sleep or to mechanical damage to the } \\
\text { upper airway. (Pediatr Res 57: 99-107, 2005) } \\
\text { BMI, body mass index } \\
\text { CPAP, continuous positive airway pressure } \\
\text { EMG, electromyogram } \\
\text { OSAS, obstructive sleep apnea syndrome } \\
\mathbf{P}_{\text {crit }} \text {, critical pressure } \\
\text { PFR, pressure-flow responses } \\
\mathbf{P}_{\mathbf{N}} \text {, nasal pressure } \\
\text { T\&A, tonsillectomy and adenoidectomy } \\
\dot{\mathbf{V}}_{\mathbf{I m a x}} \text {, maximal inspiratory airflow }\end{array}$ \\
\hline
\end{tabular}

In children, OSAS is related to adenotonsillar hypertrophy. Most children with OSAS have large tonsils and adenoids, and improve after T\&A (1). Nevertheless, studies suggest that childhood OSAS is not due to anatomic abnormalities alone. Most obvious is the fact that patients with OSAS do not obstruct during wakefulness, when upper airway muscle tone is high. Although the upper airway may be narrower in children with OSAS than in those without, there is overlap between the groups (2). A small percentage of children with adenotonsillar hypertrophy but no other known risk factors for OSAS are not cured by T\&A (1). Furthermore, a small percentage of children who were cured of their OSAS by T\&A have been reported to

Received March 15, 2004; accepted July 12, 2004.

Correspondence: Carole L. Marcus, M.B.B.Ch., Division of Pediatric Pulmonology, Wood Building, 5th Floor, Children's Hospital of Philadelphia, 34th St. \& Civic Center Blvd., Philadelphia, PA 19104; e-mail: marcus@email.chop.edu

C.L.M. was supported by Grant RR-00052 from the General Clinical Research Center, The Johns Hopkins Hospital, Baltimore, MD, and by Grant \#HL58585 from the National Heart, Lung, and Blood Institute.

DOI: 10.1203/01.PDR.0000147565.74947.14 develop a recurrence during adolescence $(3,4)$. Thus, it appears that childhood OSAS is a dynamic process resulting from a combination of structural and neuromotor abnormalities, rather than from structural abnormalities alone.

The upper airway above the level of the cartilaginous airway is a collapsible muscular tube that usually remains patent but has the potential to collapse to facilitate such functions as speech and swallowing. It comprises more than 30 pairs of muscles (5). Thus, neuromotor control of this area is important to maintain airway patency. Upper airway collapsibility during sleep is modulated by the central ventilatory drive (6). The upper airway dilatory muscles are respiratory muscles and, therefore, are activated in response to increases in the central ventilatory drive (7). We therefore hypothesized that the increased upper airway collapsibility in children with OSAS was due to decreased upper airway neuromotor responses to respiratory stimuli.

To test this hypothesis, upper airway responses were measured during sleep in school-aged children with OSAS compared with normal controls. Responses were tested in several 
ways. First of all, the upper airway response to hypercapnia was assessed. Secondly, the upper airway response to negative pressure was evaluated by applying gradual versus brief, intermittent pulses of negative pressure. CPAP suppresses upper airway muscle tone (8), whereas negative (subatmospheric) pressure results in increased upper airway tone. Thus, when the nasal pressure is changed from positive to subatmospheric, the upper airway muscles change from a hypotonic to an activated state. Previous researchers have shown that this activation of the upper airway in response to subatmospheric pressure is not immediate but occurs after approximately three breaths (9-11). Consequently, evaluation of the upper airway during the first few breaths of subatmospheric pressure application tests the relatively hypotonic upper airway, whereas evaluation during the administration of persistent subatmospheric pressure tests the activated upper airway.

\section{METHODS}

Upper airway dynamic PFR during sleep were compared between schoolaged children with OSAS and normal, nonsnoring control children. The controls were the same subjects as those participating in another study evaluating the development of upper airway responses in normal subjects (9). Baseline polysomnography was performed on all subjects, followed by PFR testing on a separate night. After PFR testing, children with OSAS undergoing T\&A (as per routine clinical practice) were invited back for postoperative evaluation.

\section{Study Group}

Children with OSAS were recruited from those referred to the Pediatric Sleep Disorders Clinic of Johns Hopkins University for evaluation of clinically suspected OSAS, who were determined to have OSAS based on a clinical polysomnogram (see below). School-aged children with OSAS related to adenotonsillar hypertrophy were recruited. The lower age limit was chosen to exclude those too young to cooperate with testing (i.e. $<5 \mathrm{y}$ of age). Patients with neurologic disease, craniofacial anomalies, or a history of previous upper airway surgery were excluded.

Healthy controls were recruited from the community by means of advertisements. Subjects with frequent (nightly) snoring, symptoms of apnea, chronic illnesses, or previous T\&A were excluded. All controls were nonobese, with a BMI $<95 \%$ predicted for age, height, and race (12).

Written informed consent was obtained from the parents or legal guardians. In addition, assent was obtained from the children. The study was approved by the Institutional Review Board of Johns Hopkins University, and studies were performed according to the Declaration of Helsinki.

\section{Baseline Polysomnography}

Overnight sleep studies included measurement of the EEG (C3/A2, O1/A2); right and left electrooculogram; submental EMG; tibial EMG; ECG; chest and abdominal wall motion (piezoelectric transducers or respiratory inductance plethysmography); oronasal airflow (three-pronged thermistor); end-tidal $\mathrm{PCO}_{2}$ (Nellcor N-1000, Van Nuys, CA); arterial oxygen saturation $\left(\mathrm{SaO}_{2}\right)$ by pulse oximetry (Nellcor N-1000) and oximeter pulse wave form. Recordings were made using the Alice 3 (Healthdyne, Marietta, GA) system. Subjects were videotaped and were attended by a polysomnography technician. Sleep architecture and arousals from sleep were analyzed using standard techniques $(13,14)$. Respiratory parameters were scored using standard pediatric methods, i.e. obstructive apneas of any length were scored (15). Hypopneas were scored if there was a qualitative decrease in oronasal airflow $\geq 50 \%$ associated with a change in the end-tidal $\mathrm{PCO}_{2}$ wave form, paradoxical breathing, and desaturation $\geq 3 \%$ and/or arousal (15).

Normative data for hypopneas in children have not been established (16). Therefore, control children with either an apnea index $\geq 1 / \mathrm{h}$ (17), or an apnea hypopnea index $(\mathrm{AHI}) \geq 5 / \mathrm{h}$, were excluded. To ensure separation between normal children and children with OSAS, children with OSAS were included if they either had an apnea index $\geq 5 / \mathrm{h}$, or an AHI $\geq 5 / \mathrm{h}$ in addition to desaturation $<90 \%$.

\section{Measurement of PFR and Upper Airway Responses}

PFR were obtained during a second, overnight study, using modifications of previously published techniques $(6,9,18)$. Upper airway function was measured under the following conditions, in random order:

1. Stepwise, decremental, steady state decreases in nasal pressure. This was hypothesized to result in sequential activation of the upper airway ("gradual" technique).

2. Acute, transient, intermittent drops in nasal pressure from a baseline holding pressure. This was hypothesized to result in a relatively hypotonic airway ("intermittent" technique).

3. Decremental decreases in nasal pressure during $\mathrm{CO}_{2}$ breathing. $\mathrm{CO}_{2}$ challenges were performed in all children with OSAS, and in the first 10 control children studied.

During PFR, in addition to the above routine polysomnographic measurements, airflow and nasal pressure were measured quantitatively. The subject wore a gel CPAP mask (Respironics, Pittsburgh, PA) attached to a heated pneumotachometer (Hans Rudolph, Inc., Kansas City, MO) and transducer (Validyne Engineering Corp., Northridge, CA). Nasal pressure $\left(\mathrm{P}_{\mathrm{N}}\right)$ was measured at the mask, using a differential pressure transducer referenced to atmosphere. End-tidal $\mathrm{PCO}_{2}$ was measured via a port on the mask (Ametek, Paoli, PA). Transcutaneous $\mathrm{PCO}_{2}$ was also measured (Radiometer, Paramus, $\mathrm{NJ})$. A thermistor was placed at the mouth to detect oral breathing. Subjects who mouth-breathed were fitted with an oronasal mask. Pressure and flow signals were acquired using DATAQ Instruments (Akron, $\mathrm{OH}$ ) hardware and WinDaq software, and simultaneously displayed on the Alice system. Positive or subatmospheric nasal pressure $\left(\mathrm{P}_{\mathrm{N}}\right)$ was administered using a device consisting of dual CPAP machines, one of which was modified by Respironics to provide subatmospheric pressure. Rapid changes between positive and subatmospheric pressure were accomplished using a toggle switch. The equipment delivered a $\mathrm{P}_{\mathrm{N}}$ of +22 to $-22 \mathrm{~cm} \mathrm{H}_{2} \mathrm{O}$. Measurements were performed during slow wave sleep, as obstructive apneas are rare during this sleep stage (19). Attempts to perform PFR during REM sleep were unsuccessful due to subject arousal.

Gradual technique. Studies were initiated with the subjects breathing sufficient CPAP to overcome inspiratory airflow limitation. Flow limitation was determined by the characteristic wave form pattern, consisting of increasing inspiratory flow followed by a mid-inspiratory plateau $(20,21)$, rather than by using invasive esophageal pressure measurements in these young volunteers (22). $\mathrm{P}_{\mathrm{N}}$ was then decreased in $2 \mathrm{~cm} \mathrm{H}_{2} \mathrm{O}$ steps every $30 \mathrm{~s}$ until flow approached zero or the subject aroused.

Intermittent technique. Studies were initiated with the subjects breathing sufficient CPAP to overcome inspiratory airflow limitation (the holding pressure). $\mathrm{P}_{\mathrm{N}}$ was then acutely decreased by $2 \mathrm{~cm} \mathrm{H}_{2} \mathrm{O}$ for three to five breaths, following which it was rapidly returned to the holding pressure (Fig. 1). $\mathrm{P}_{\mathrm{N}}$ was dropped repeatedly to incrementally lower levels, with a return each time to the holding pressure, until either flow approached zero or the subject aroused. In all controls, and in all but one of the children with OSAS, $\mathrm{P}_{\mathrm{N}}$ was decreased to subatmospheric levels during the pressure drops. Using intraoral genioglossal EMG measurements (23) in normal children, we have previously shown that the gradual runs result in a gradual increase in EMG activity as $\mathrm{P}_{\mathrm{N}}$ becomes increasingly negative. In contrast, during intermittent runs, the EMG activity is at a low level for the first three breaths of negative pressure, and begins to increase by the fourth breath (9).

$\mathrm{CO}_{2}$ responses. $\mathrm{CO}_{2}$ responses were carried out using the gradual technique. Studies were initiated with the subject breathing CPAP sufficient to overcome inspiratory airflow limitation. $\mathrm{CO}_{2}$ was introduced via a fine nasal cannula beneath the mask until the transcutaneous $\mathrm{PCO}_{2}$ increased by $3 \mathrm{~mm} \mathrm{Hg}$. This small change in $\mathrm{PCO}_{2}$ was used as larger changes, in conjunction with subatmospheric nasal pressure, caused arousal from sleep. On average, this required $0.4 \mathrm{LPM}$ of $100 \% \mathrm{CO}_{2}$ blended with the flow through the CPAP circuit. The gel mask was able to make a seal around the cannula. Transcutaneous $\mathrm{PCO}_{2}$ was measured instead of end-tidal $\mathrm{PCO}_{2}$, as the end-tidal wave form could not be measured during the administration of subatmospheric pressure. The response time of the transcutaneous $\mathrm{CO}_{2}$ electrode to a step change 


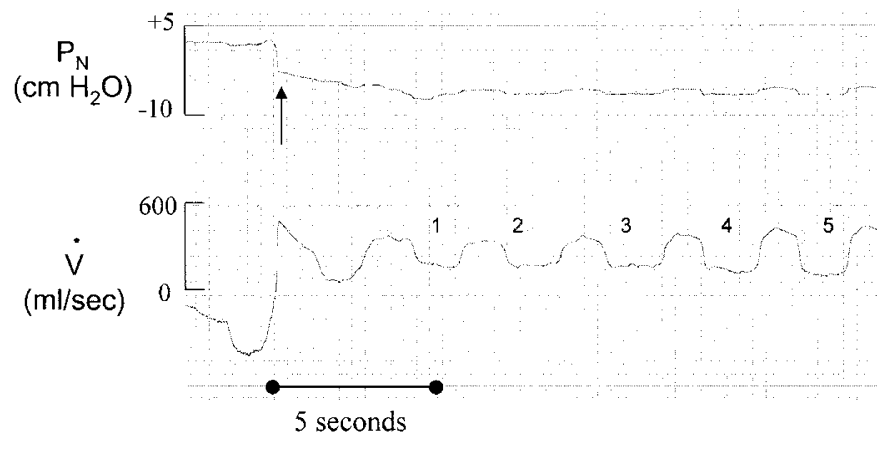

Figure 1. A tracing is shown for a control child during an intermittent PFR run. $\mathrm{P}_{\mathrm{N}}$ was decreased at the time point indicated by the arrow. The first breath (not numbered) is a transitional breath during the pressure change. The sudden drop in $\mathrm{P}_{\mathrm{N}}$ results in a decrease in flow, as well as a flow-limited breathing pattern, during the first three breaths. Subsequently, there is an increase in flow for breaths 4 and 5, as well as a transition to a nonflow-limited pattern, suggesting that activation of the upper airway muscles has occurred.

increase in $\mathrm{CO}_{2}$ was $35 \mathrm{~s}$. The median time for the transcutaneous $\mathrm{PCO}_{2}$ monitor to reach the goal of $3 \mathrm{~mm} \mathrm{Hg}$ above baseline was $102 \mathrm{~s}$. The subject breathed a steady flow of $\mathrm{CO}_{2}$ for 3 min. $\mathrm{P}_{\mathrm{N}}$ was then decreased in $2 \mathrm{~cm}_{2} \mathrm{O}$ steps until flow approached zero or the subject aroused. $\mathrm{CO}_{2}$ administration continued throughout the challenge.

\section{Data Analysis}

The average mid-inspiratory flow was measured from the lowest two consecutive breaths at each level of $\mathrm{P}_{\mathrm{N}}$. Pressure-flow curves were constructed by plotting maximal inspiratory airflow $\left(\dot{\mathrm{V}}_{\text {Imax }}\right)$ of flow-limited breaths against $\mathrm{P}_{\mathrm{N}} . \mathrm{P}_{\mathrm{N}}$ versus $\dot{\mathrm{V}}_{\text {Imax }}$ curves were fitted by least squares linear regression. The critical pressure $\left(\mathrm{P}_{\text {crit }}\right)$ was defined as the $\mathrm{x}$ axis intercept of the regression line $\left(\dot{\mathrm{V}}_{\text {Imax }}=0\right)$. As previously demonstrated, many of the normal children were able to maintain airflow even at markedly subatmospheric pressures (Fig. 1) (6). Thus, the x-intercept could not be determined without extreme extrapolation, and therefore $\mathrm{P}_{\text {crit }}$ could not always be measured. As the equipment provided a maximum negative pressure of $-22 \mathrm{~cm} \mathrm{H}_{2} \mathrm{O}$, we arbitrarily elected to assign a threshold value of $-25 \mathrm{~cm} \mathrm{H}_{2} \mathrm{O}$ to $\mathrm{P}_{\text {crit }}$ data that were extrapolated to $<-25 \mathrm{~cm} \mathrm{H}_{2} \mathrm{O}$ (9). This allowed us to apply statistical methods to the $\mathrm{P}_{\text {crit }}$ data. In addition, the slope of the upstream-pressure-flow curve was also used to characterize the upper airway response (6).

\section{Statistical Analysis}

Nonparametric methods were used as most data were not normally distributed. All results are expressed as median (range) unless otherwise specified. Differences were compared between groups using the Wilcoxon rank sum test. Differences between conditions for the same individual were compared using the Wilcoxon signed rank test. The mean difference in inspiratory airflow between individual breaths as a percentage of baseline flow during the intermittent challenges was calculated for each patient and analyzed using the Wilcoxon signed rank test.

\section{RESULTS}

Study population. Thirty-four subjects were recruited. One control had an abnormal baseline sleep study and was excluded. Thus, 33 subjects competed the study: 11 children with OSAS and 22 controls. Successful gradual responses were completed in all subjects, and successful intermittent responses in 10 children with OSAS and 20 controls. $\mathrm{CO}_{2}$ challenges were performed in all children with OSAS, and in the first ten normal children. One additional 5-y-old child with OSAS was subsequently recruited for evaluation of awake pressure-flow relationships. Her data are discussed separately. Seven of the 11 children with OSAS agreed to repeat evaluation after surgical treatment.

Subject demographics and baseline polysomnography results are shown in Table 1. Controls were older than those with OSAS. Four $(36 \%)$ of the children with OSAS were obese, whereas, by definition, none of the controls was obese. However, there was no difference in mean BMI between the two groups.

Response to hypercapnia. The $\mathrm{CO}_{2}$ responses were compared with the gradual rather than the intermittent room air responses, as all subjects underwent gradual response testing, but not all subjects successfully completed intermittent testing. In the children with OSAS, median transcutaneous $\mathrm{PCO}_{2}$ was initially $48 \mathrm{~mm} \mathrm{Hg}$ and increased to $52 \mathrm{~mm} \mathrm{Hg}$ by the end of the challenge. In the controls, the median transcutaneous $\mathrm{P}_{2}$ increased from $46 \mathrm{~mm} \mathrm{Hg}$ to $48 \mathrm{~mm} \mathrm{Hg}$.

In the normal children, hypercapnia resulted in increased flow for a given $\mathrm{P}_{\mathrm{N}}$. There appeared to be a complex interaction between the response to $\mathrm{CO}_{2}$ and the response to negative pressure as $\mathrm{P}_{\mathrm{N}}$ decreased (9). Therefore, data were evaluated by comparing the maximal inspiratory flow $\left(\dot{\mathrm{V}}_{\mathrm{Imax}}\right)$ when subjects were breathing room air versus $\mathrm{CO}_{2}$ at atmospheric pressure $\left(\mathrm{P}_{\mathrm{N}}=0 \mathrm{~cm} \mathrm{H} \mathrm{H}_{2} \mathrm{O}\right) . \dot{\mathrm{V}}_{\text {Imax }}$ measurements in the flowlimited state reflect upper airway properties and are independent of changes in ventilatory drive. Therefore, only flowlimited breaths were evaluated, to assess the effect of $\mathrm{CO}_{2}$ on the upper airway.

Ninety percent of controls had an increase in $\dot{V}_{\text {Imax }}$ in response to hypercapnia $(p<0.01)$ (Table 2$)$. In contrast, only $27 \%$ of children with OSAS had a response to $\mathrm{CO}_{2}$ (not significant). These were not all the same subjects that showed a response to negative pressure (below). There was a significant difference in the change in $\dot{\mathrm{V}}_{\text {Imax }}$ between the two conditions in the children with OSAS versus controls $(p<0.01)$.

Gradual versus intermittent pressure-flow measurements. As in previous studies, control children had an airway that was very resistant to collapse when the gradual technique was used (6). This resulted in a flat slope of the pressure-flow curve, and a $\mathrm{P}_{\text {crit }}$ that was unmeasurable (i.e. more negative than $-25 \mathrm{~cm}$ $\mathrm{H}_{2} \mathrm{O}$ ) in $70 \%$ of subjects. In contrast, the airway was more collapsible when the intermittent technique was used, with a steeper slope, and an unmeasurable $\mathrm{P}_{\text {crit }}$ in only $50 \%$ of subjects (Figs. 2, 3). Therefore, the intermittent technique was used as the baseline to which the other conditions could be compared.

Table 1. Study group

\begin{tabular}{lccc}
\hline & Controls & OSAS & $p$ Value \\
\hline No. & 22 & 11 & \\
Age (y) & $11(6-13)$ & $8(5-10)$ & 0.005 \\
Males (no., \%) & $14(64)$ & $5(45)$ & NS \\
BMI (kg/m²) & $20(15-27)$ & $18(14-31)$ & NS \\
Apnea hypopnea index (no./h) & $0(0-1)$ & $15(6-55)$ & 0.0001 \\
Arterial oxygen saturation nadir (\%) & $96(91-98)$ & $84(54-91)$ & 0.0001 \\
Peak end-tidal $\mathrm{PCO}_{2}(\mathrm{~mm} \mathrm{Hg})$ & $49(40-57)$ & $52(39-64)$ & 0.05 \\
\hline
\end{tabular}

All data displayed as median (range) unless otherwise specified. 
Table 2. Effect of $\mathrm{CO}_{2}$ on $\dot{V}_{\text {Imax }}$ at atmospheric pressure $\left(P_{N}=0\right)$ during sleep

\begin{tabular}{lcccc}
\hline & $\begin{array}{c}\dot{\mathrm{V}}_{\text {Imax }} \\
\text { on room air } \\
(\mathrm{mL} / \mathrm{s})\end{array}$ & $\begin{array}{c}\Delta \dot{\mathrm{V}}_{\text {Imax }} \\
(\% \text { baseline })\end{array}$ & $\begin{array}{c}\text { Subjects with } \\
\text { increased } \\
\dot{\mathrm{C}}_{\text {Imax }} \text { on } \mathrm{CO}_{2}(\%)\end{array}$ \\
\hline Controls & 10 & $154(44-232)$ & $+85(-33-564)^{*, \dagger}$ & 90 \\
OSAS & 11 & $82(0-276)$ & $-17(-222-126)$ & 27 \\
\hline
\end{tabular}

Data shown as median (range).

$* p<0.01$ for controls breathing room air $v s \mathrm{CO}_{2}$.

$\dagger p<0.01$ for $\Delta \dot{\mathrm{V}}_{\text {Imax }}$ for controls $v s$ OSAS.

During intermittent challenges, the median holding pressure was $2.3 \mathrm{~cm} \mathrm{H}_{2} \mathrm{O}$ for controls and $6.4 \mathrm{~cm} \mathrm{H}_{2} \mathrm{O}$ for children with OSAS $(p<0.0001)$. A typical pressure-flow tracing from a control during an intermittent challenge is shown in Figure 1. After the drop in $\mathrm{P}_{\mathrm{N}}$, the first three breaths were flow-limited, and had small flows. Breaths 4 and 5 showed a transition to a nonflow-limited pattern, associated with larger flows. This indicates that activation of the upper airway muscles started occurring at that point. To evaluate this objectively, the mean difference in inspiratory flow (as a percentage of baseline flow) between breath 1 and breath 2 after the drop in $\mathrm{P}_{\mathrm{N}}$ was measured for each subject. Similarly, the differences between breath 1 and breath 3 , and breath 1 and breath 5 , were measured. In the controls, there was no significant difference in flow between breath 1 versus breath 2 , or breath 1 versus breath 3. However, there was a significant increase in flow between breaths 1 versus 5, suggesting that upper airway activation or other mechanisms for increased flow occurred only after the first few breaths $(p<0.05)$. In contrast, children with OSAS had no significant difference in flow between breath 1 versus either breath 2, breath 3 or breath 5, suggesting a lack of upper airway activation.

With the intermittent technique, only one child with OSAS (10\%) had a flat slope and a $\mathrm{P}_{\text {crit }}<-25 \mathrm{~cm} \mathrm{H}_{2} \mathrm{O}$, versus $50 \%$ of controls. $\mathrm{P}_{\text {crit }}$ was significantly less negative in the children with OSAS than controls $(p=0.0003)$, indicating a more collapsible upper airway; the slope was similar (Table 3). Using the gradual technique, both $\mathrm{P}_{\text {crit }}(p<0.0001)$ and slope $(p=0.004)$ were greater in the children with OSAS than controls.

Figure 3 and Table 3 demonstrate the group changes in slope for the gradual versus the intermittent technique airway. The controls tended to have a flatter slope and a more negative $\mathrm{P}_{\text {crit }}$ with the gradual technique; $85 \%$ of controls had a flatter slope with the gradual compared with the intermittent technique $(p<$ 0.01 ). There was no significant difference in $\mathrm{P}_{\text {crit }}$ between the two conditions, probably because many subjects had the arbitrary cutoff of $-25 \mathrm{~cm} \mathrm{H}_{2} \mathrm{O}$ applied to both states. Using extrapolated data without the cutoff (Fig. 3), there was clearly a visual difference in $\mathrm{P}_{\text {crit }}$ between the two conditions. In contrast to the normal children, the children with OSAS did not have a significant difference in either slope or $\mathrm{P}_{\text {crit }}$ between the gradual and intermittent conditions. Only $30 \%$ of children with OSAS had a flatter slope and more negative $\mathrm{P}_{\text {crit }}$ with the gradual technique (not significant).

To assess the effect of the discrepancy in age between the control and the OSAS group, the correlation between age and
$\mathrm{P}_{\text {crit }}$, and age and slope, was determined for the control group. There was no significant correlation between any of these parameters, and all of the correlation coefficients were very low.

During PFR, there was little change in gas exchange. The median $\mathrm{SaO}_{2}$ change from baseline was $0 \%$ for the intermittent technique and $-1 \%$ for the gradual technique. Only two individuals (both of whom had OSAS) desaturated more than $3 \%$; one desaturated to $91 \%$ and the other to $92 \%$. The median change in transcutaneous $\mathrm{PCO}_{2}$ was $0 \mathrm{~mm} \mathrm{Hg}$ for the intermittent technique and $1 \mathrm{~mm} \mathrm{Hg}$ for the gradual technique; the largest individual increase in $\mathrm{PCO}_{2}$ was $2 \mathrm{~mm} \mathrm{Hg}$.

Oronasal versus nasal mask. In children who mouthbreathed, oronasal masks were used instead of nasal masks. To ensure that this did not affect results, gradual runs were performed in one control using a nasal mask versus an oronasal mask. Both runs were performed during slow wave sleep on the same night. The resultant pressure-flow curves were virtually identical (Fig. 4).

Tonsillectomy and adenoidectomy. Seven children with OSAS agreed to return for reevaluation after T\&A. The following data relate to these seven subjects. There were no significant differences in demographics, polysomnographic results, or initial PFR between the seven who returned for follow-up and the four who did not. Baseline polysomnography was repeated $13 \pm 7 \mathrm{wk}$ postoperatively. Six of the seven had resolution of their OSAS, with a mean postoperative AHI of $1 \pm 1 / \mathrm{h}$, and normal gas exchange. The seventh child, who was obese, had some improvement postoperatively, but continued to have severe OSAS (AHI 55/h preoperatively versus $22 / \mathrm{h}$ postoperatively). She showed only a slight improvement in PFR values postoperatively $\left(\mathrm{P}_{\text {crit }}-9\right.$ versus $-6 \mathrm{~cm} \mathrm{H}_{2} \mathrm{O}$ preoperatively, slope 14 versus $13 \mathrm{~mL} / \mathrm{s} / \mathrm{cm} \mathrm{H}_{2} \mathrm{O}$ ).

Postoperatively, there was a trend toward an increase in $\dot{\mathrm{V}}_{\text {Imax }}$ in response to hypercapnia in the responders, with all patients showing an increase in flow [median $\Delta \dot{\mathrm{V}}_{\text {Imax }}$ at atmospheric $\mathrm{P}_{\mathrm{N}}$ when breathing $\mathrm{CO}_{2}$ versus room air, as a percentage of baseline, of 42 ( -24 to 90$) \mathrm{mL} / \mathrm{s}$ ], although this did not reach significance. Similarly, six of the seven children had a trend toward normalization of PFR responses postoperatively, although data did not reach a significant level (Table 4; Fig. 5). The seventh child was an outlier who had a flat PFR curve preoperatively but a steeper curve postoperatively, despite resolution of her OSAS. Postoperatively, six of the seven subjects had a more negative $\mathrm{P}_{\text {crit }}$ compared with preoperatively, with both the intermittent and gradual techniques. However, the drop in $\mathrm{P}_{\text {crit }}$ was more marked with the gradual technique. Six had a flatter slope with the gradual technique postoperatively, whereas only three had a flatter slope with the intermittent technique.

The postoperative $\mathrm{P}_{\text {crit }}$ and slopes were compared between the surgical responders and the controls. Postoperatively, the intermittent $\mathrm{P}_{\text {crit }}$ remained elevated in the children with OSAS compared with the controls.

Awake $\boldsymbol{P}_{\text {crit }}$ An alternative explanation for the lack of response to $\mathrm{CO}_{2}$ in the OSAS group could be that the children's upper airway was already maximally activated by negative pressure, and therefore hypercapnia could not elicit a 
Control

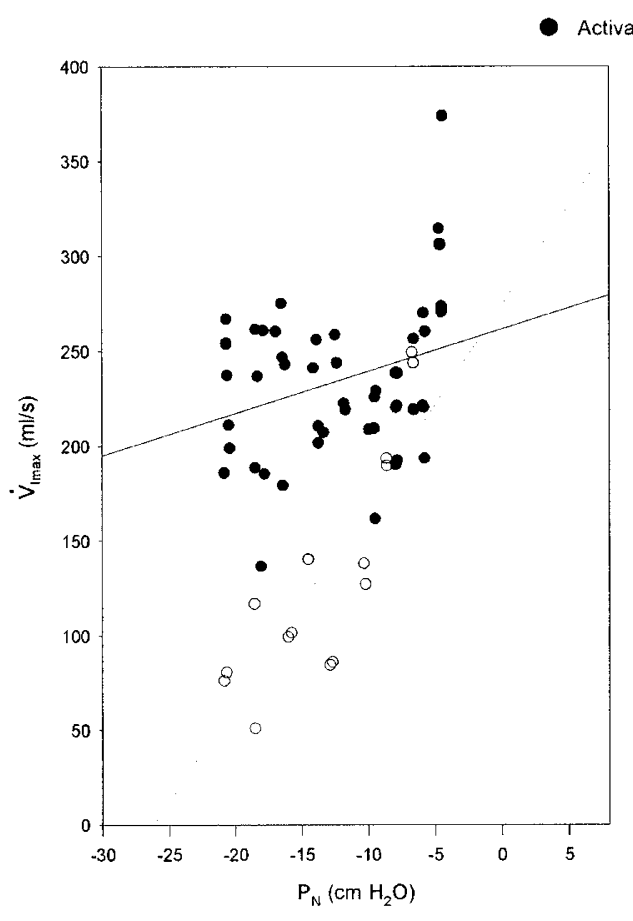

OSAS

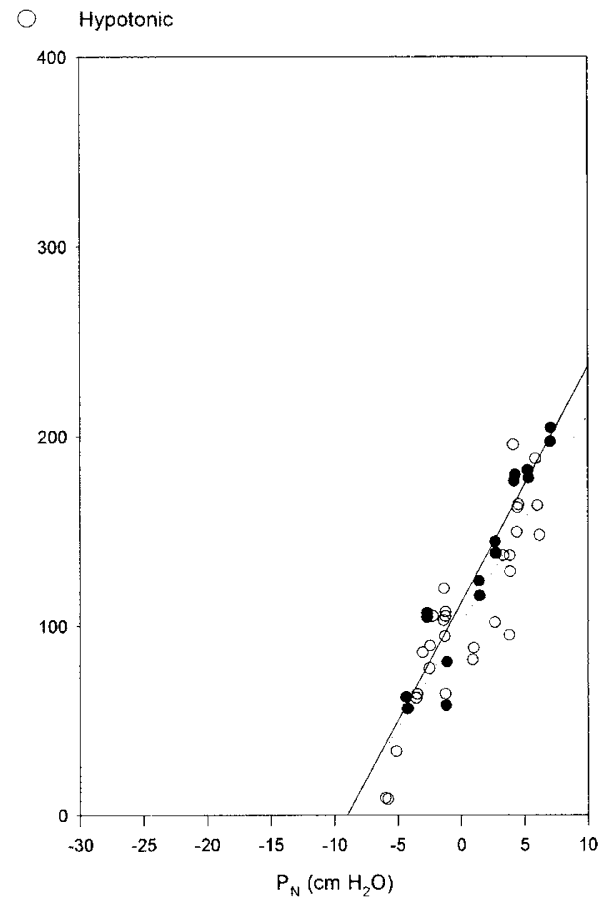

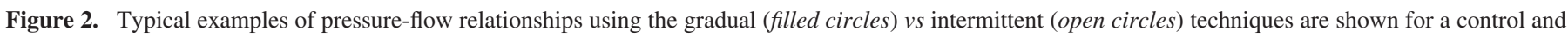

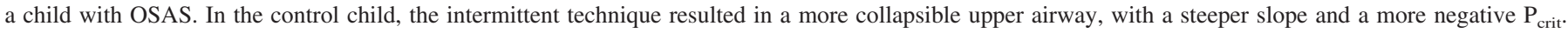

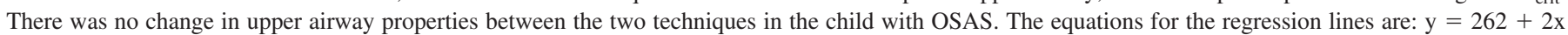

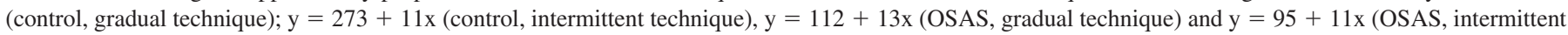
technique).
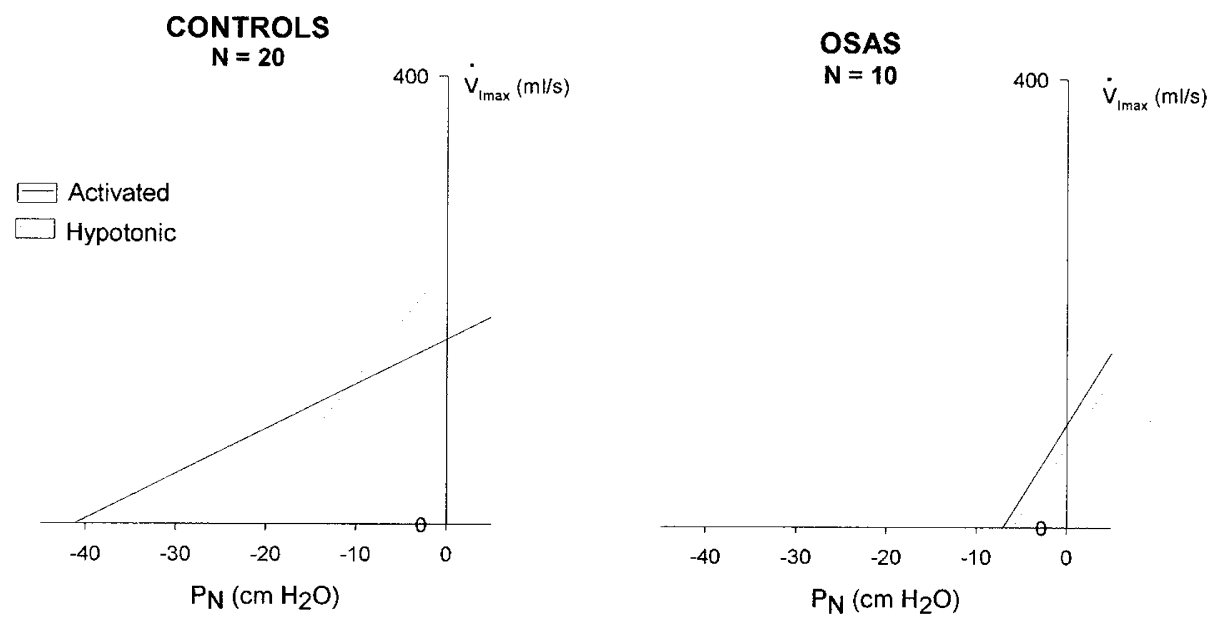

Figure 3. A schematic diagram of the pooled group median pressure-flow data for the gradual (solid line) vs intermittent (dotted line) techniques is shown for all subjects in whom paired data were available. Controls are shown in the left panel, and children with OSAS on the right. Note that the figures show the raw $\mathrm{P}_{\text {crit }}$ data without the arbitrary cutoff of $-25 \mathrm{~cm} \mathrm{H}_{2} \mathrm{O}$. Control children showed a significant difference between the two conditions, in comparison to OSAS (see text for $p$ values).

further response. To evaluate this possibility, $\mathrm{P}_{\text {crit }}$ measurements were obtained during wakefulness in two OSAS subjects; the 10-y-old child who had persistent OSAS following T\&A and an additional 5-y-old child with OSAS (AHI 30/h, $\mathrm{SaO}_{2}$ nadir $70 \%$ ). Subjects were studied in the evening in the supine position, using the gradual technique. Wakefulness was verified by both EEG and audiovisual monitoring. In both subjects, the upper airway was very resistant to collapse during wakefulness. The post T\&A subject had a slope of $3 \mathrm{~mL} / \mathrm{s} / \mathrm{cm}$ $\mathrm{H}_{2} \mathrm{O}$ and $\mathrm{P}_{\text {crit }}$ of $-25 \mathrm{~cm} \mathrm{H}_{2} \mathrm{O}$ awake versus $13 \mathrm{~mL} / \mathrm{s} / \mathrm{cm} \mathrm{H}_{2} \mathrm{O}$ and $-9 \mathrm{~cm} \mathrm{H}_{2} \mathrm{O}$ during gradual runs asleep; the other OSAS subject had a slope of $1 \mathrm{~mL} / \mathrm{s} / \mathrm{cm} \mathrm{H}_{2} \mathrm{O}$ and $\mathrm{P}_{\text {crit }}$ of $-25 \mathrm{~cm} \mathrm{H}_{2} \mathrm{O}$ awake versus $9 \mathrm{~mL} / \mathrm{s} / \mathrm{cm} \mathrm{H}_{2} \mathrm{O}$ and $-12.5 \mathrm{~cm} \mathrm{H}_{2} \mathrm{O}$ during gradual runs asleep.

\section{DISCUSSION}

This study has shown that children with OSAS lack upper airway neuromotor responses to hypercapnia and negative pressure during sleep, in contrast to normal children. In addi- 
Table 3. Gradual vs intermittent pressure-flow relationships

\begin{tabular}{cccc}
\hline Measure & \multicolumn{1}{c}{ Controls } & \multicolumn{1}{c}{ OSAS } & $p$ Value \\
\hline $\begin{array}{c}\text { Intermittent } \mathrm{P}_{\text {crit }} \\
\left(\mathrm{cm} \mathrm{H} \mathrm{H}_{2} \mathrm{O}\right)\end{array}$ & $-25(-7$ to -25$)$ & $-5(-1$ to -25$)$ & 0.0003 \\
$\begin{array}{c}\text { Intermittent slope } \\
\left(\mathrm{mL} / \mathrm{s} / \mathrm{cm} \mathrm{H}_{2} \mathrm{O}\right)\end{array}$ & $9 *(-5$ to 26$)$ & $10(3$ to 22$)$ & 0.52 \\
$\begin{array}{c}\text { Gradual } \mathrm{P}_{\text {crit }} \\
\left(\mathrm{cm} \mathrm{H} \mathrm{H}_{2} \mathrm{O}\right)\end{array}$ & $-25(-9$ to -25$)$ & $-7(-2$ to -25$)$ & 0.0001 \\
$\begin{array}{c}\text { Gradual slope } \\
\left(\mathrm{mL} / \mathrm{s} / \mathrm{cm} \mathrm{H}_{2} \mathrm{O}\right)\end{array}$ & $4(-9$ to 21$)$ & $13(1$ to 26$)$ & 0.004 \\
\hline
\end{tabular}

Data shown as median (range). One patient with OSAS was an outlier with a $\mathrm{P}_{\text {crit }}$ value of $-25 \mathrm{~cm} \mathrm{H}_{2} \mathrm{O}$.

* Controls intermittent $v s$ gradual slope: $p<0.01$.

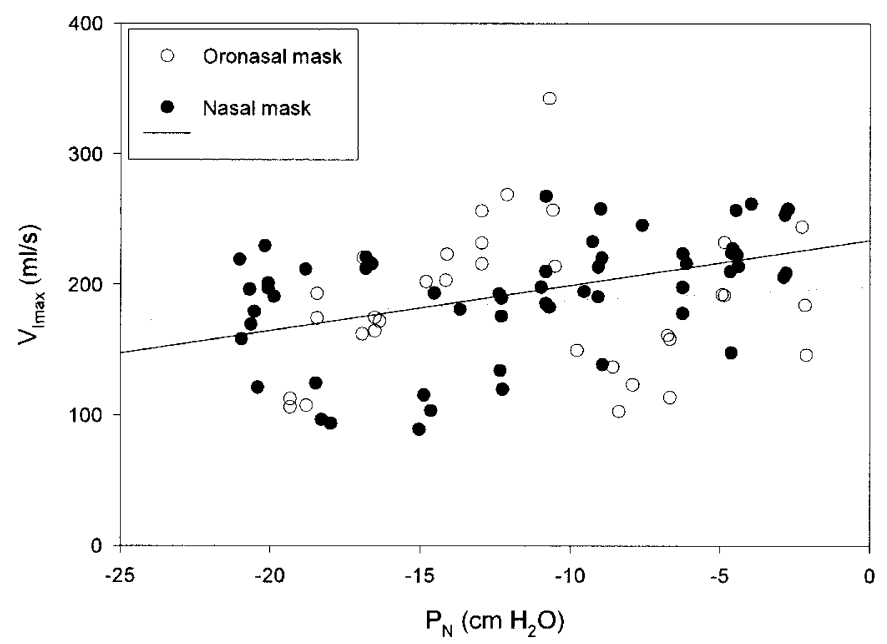

Figure 4. The pressure-flow relationship is shown for a control child wearing a nasal mask (filled circles) $v s$ an oronasal mask (open circles). The pressureflow curves were similar between the two conditions. The equations for the regression lines are $\mathrm{y}=232+3.5 \mathrm{x}$ (nasal mask) and $\mathrm{y}=197+\mathrm{x}$ (oronasal mask).

Table 4. Effect of T\&A on OSAS

\begin{tabular}{|c|c|c|c|}
\hline Measure & OSAS Pre T\&A & OSAS Post T\&A & Controls \\
\hline No. & 7 & 7 & 22 \\
\hline $\begin{array}{l}\text { Intermittent } \mathrm{P}_{\text {crit }} \\
\quad\left(\mathrm{cm} \mathrm{H} \mathrm{H}_{2} \mathrm{O}\right)\end{array}$ & $-6(-1$ to -25$)$ & $-14 *(-3$ to -21$)$ & $-25(-7$ to -25$)$ \\
\hline $\begin{array}{l}\text { Intermittent slope } \\
\left(\mathrm{mL} / \mathrm{s} / \mathrm{cm} \mathrm{H}_{2} \mathrm{O}\right)\end{array}$ & 10 (3 to 22$)$ & 11 (6 to 18$)$ & $9(-5$ to 26$)$ \\
\hline $\begin{array}{l}\text { Gradual } \mathrm{P}_{\text {crit }} \\
\left(\mathrm{cm} \mathrm{H}_{2} \mathrm{O}\right)\end{array}$ & $-7(-2$ to -25$)$ & $-25(-9$ to -25$)$ & $-25(-9$ to -25$)$ \\
\hline $\begin{array}{l}\text { Gradual slope } \\
\quad\left(\mathrm{mL} / \mathrm{s} / \mathrm{cm} \mathrm{H}_{2} \mathrm{O}\right)\end{array}$ & 11 (1 to 26$)$ & 5 (2 to 22$)$ & $4(-9$ to 21$)$ \\
\hline
\end{tabular}

Data shown as median (range). Normal children are shown for the purpose of comparison. There were no significant differences in any of the parameters before $v s$ after T\&A. However, the intermittent $\mathrm{P}_{\text {crit }}$ remained less negative in the children with OSAS after T\&A, compared with the controls.

$* p<0.01$ for OSAS post T\&A $v s$ controls.

tion, children with OSAS have a more collapsible upper airway using the intermittent (hypotonic) technique than normal children, indicating the presence of structural differences between the groups (such as adenotonsillar hypertrophy). After T\&A, there was a modest trend toward improvement in structural factors. However, the major postoperative change was the trend toward normalization of upper airway neuromotor responses.

\section{PFR}

In the hypotonic state, the upper airway behaves like a Starling resistor $(6,10,21,24-26)$. This model has been well described for both children and adults. The critical closing pressure $\left(\mathrm{P}_{\text {crit }}\right)$ has been used to characterize upper airway function. In both children and adults with sleep-disordered breathing, ranging from primary snoring to obstructive sleep apnea, the value of $\mathrm{P}_{\text {crit }}$ correlates with the degree of obstruction $(21,27,28)$ and decreases after surgical treatment of obstructive apnea $(21,26)$. Although this model is useful, recent studies have shown that, during natural sleep, the model is modified by the effect of upper airway neuromotor reflexes in response to factors such as subatmospheric pressure and $\mathrm{CO}_{2}$ $(6,9,10)$. This effect of these reflexes is particularly pronounced in normal young children. As a result of upper airway neuromotor activation, normal sleeping children are often able to maintain airflow despite the application of large amounts of subatmospheric pressure $(6,9)$. In these cases, $\mathrm{P}_{\text {crit }}$ often cannot be measured. Therefore, the slope of the pressure-flow relationship is used to characterize upper airway collapsibility $(6,9)$. It has been shown that that the intermittent PFR technique results in a relatively hypotonic airway, whereas the gradual technique results in an activated airway $(9-11)$. Thus, use of the intermittent technique allows us to delineate the effect of structural factors on upper airway function, whereas use of the gradual technique allows us to determine the effect of neuromotor factors.

It is unlikely that the intermittent technique used in this study eliminated all muscle tone. More likely, there was a reduction in muscle activation, but some preservation of baseline tone, i.e. relative hypotonia rather than atonia. This is suggested by comparing our data with that of Isono et al. (29). They measured the upper airway closing pressure in the anesthetized, paralyzed state, i.e. atonia. Different methods were used in their study, so direct comparisons of absolute values from the two studies may not be valid. However, in their study, both children with OSAS and normal children had a higher closing pressure than the $\mathrm{P}_{\text {crit }}$ in the current study. Nevertheless, they also found that children with OSAS had a more collapsible upper airway than normal children, indicating that children with OSAS had different structural properties of the upper airway, predisposing them to airway collapse.

The assumption in this study is that the intermittent technique resulted in upper airway hypotonia. This is based on EMG studies performed in adults (11), as well as studies performed by us in school-aged children using the same techniques (9). Infants have been shown to have a much more rapid upper airway response to drops in negative pressure; thus, the results of this study cannot be extrapolated to infants with OSAS $(9,30,31)$. In the current study, instead of measuring EMG activity in addition to the many other parameters measured, upper airway responses were assessed by evaluating changes in airflow during flow-limited breaths. Therefore, to provide supportive data that the intermittent technique did in fact represent a relatively hypotonic airway, we analyzed the difference in flow between breath 1 after the drop in $\mathrm{P}_{\mathrm{N}}$ and the subsequent breaths. In the normal children, a change to a 

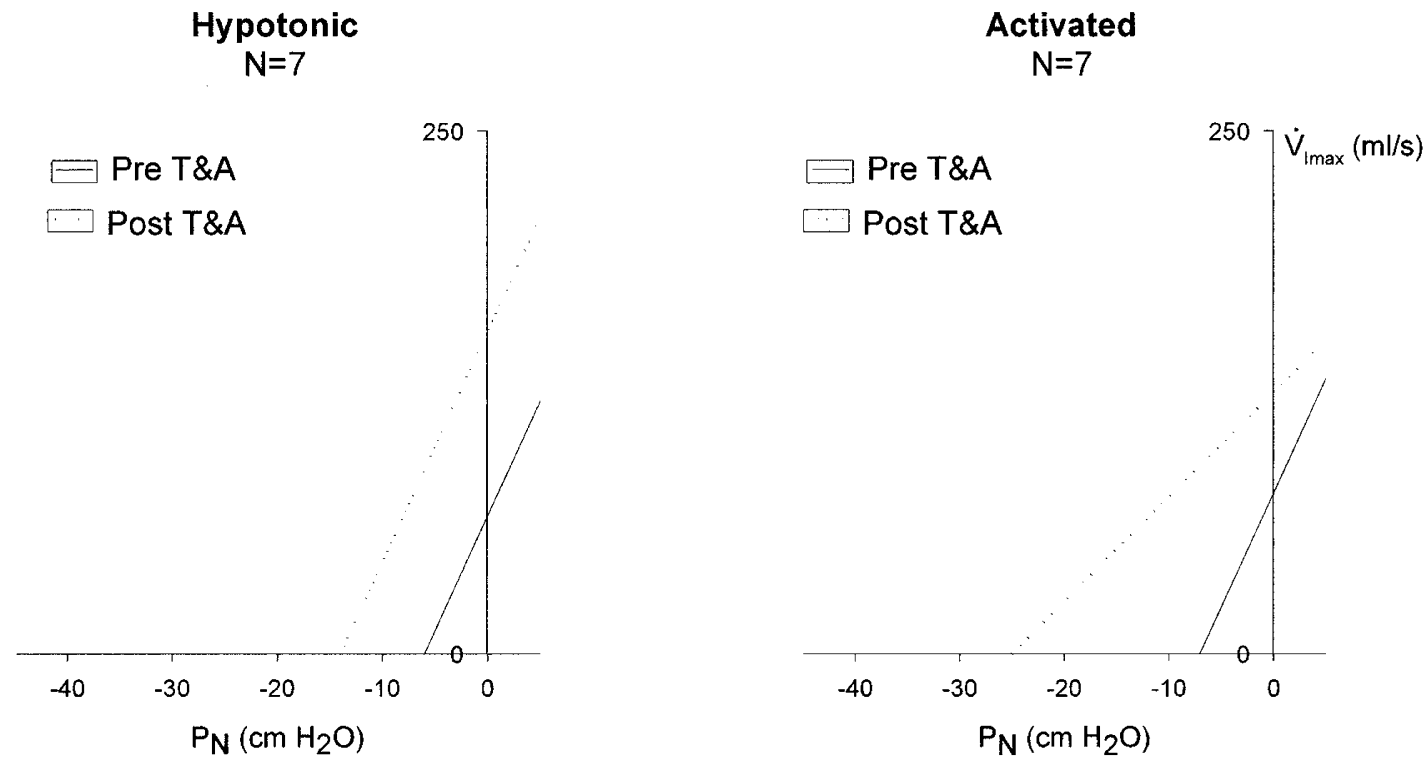

Figure 5. A schematic diagram of the pooled group median pressure-flow data before (solid line) and after (dotted line) T\&A are shown for the seven subjects with OSAS who returned for postoperative reevaluation. Intermittent responses are shown on the left panel, and gradual responses on the right. Note that the figures show the raw $\mathrm{P}_{\text {crit }}$ data without the arbitrary cutoff of $-25 \mathrm{~cm} \mathrm{H}_{2} \mathrm{O}$. There was a trend toward a flatter slope and a more negative $\mathrm{P}_{\text {crit }}$ postoperatively, particularly with the gradual technique.

nonflow-limited pattern typically occurred after breath 3 (Fig. 1). In fact, flow did not change between breaths 1 and breaths 2 and 3 , but increased significantly by breath 5 . This confirmed that normal children had neuromotor activation after the first three breaths, although children with OSAS did not. Nevertheless, further studies including EMG measures would be desirable.

\section{STRUCTURAL FACTORS}

Children with OSAS had a more collapsible upper airway using the intermittent technique than the controls, demonstrating the presence of a structural component. This was most likely due to adenotonsillar hypertrophy. The tonsils and adenoids are increased in children with OSAS (2), and apnea resolves after $\mathrm{T} \& \mathrm{~A}$ in the vast majority of otherwise-healthy children (1). As expected, we found that there was a trend toward normalization of the intermittent PFR curve after resection of the tonsils and adenoids. However, the intermittent $\mathrm{P}_{\text {crit }}$ remained elevated compared with controls, suggesting the persistence of other structural abnormalities postoperatively. Adults with OSAS have been shown to have a narrower pharynx than controls (32). Similarly, it is possible that children with OSAS have an underlying narrow pharyngeal airway, but that clinical OSAS occurs when this narrowing is exacerbated by the development of adenotonsillar hypertrophy.

\section{NEUROMOTOR CONTROL OF THE UPPER AIRWAY}

In addition to structural factors, upper airway function is modulated by neuromotor factors. These neuromotor factors include sleep state, chemoreceptor input (7) and upper airway pressure receptors (33). The literature suggests that the upper airway response to both $\mathrm{CO}_{2}$ and subatmospheric pressure is a centrally mediated reflex (9). In the current study, both $\mathrm{CO}_{2}$ and subatmospheric pressure application resulted in increased flow and a change from a flow-limited to a nonflow-limited pattern. This was probably due to stimulation of the CNS, resulting in augmentation of upper airway neuromotor tone $(7,34,35)$. Previously, we showed that children with OSAS had normal ventilatory responses to hypoxia and hypercapnia during both wakefulness (36) and sleep (35). Thus, their overall ventilatory drive appears to be normal. However, we hypothesized that the CNS role in augmenting upper airway responses to stimuli was abnormal. This hypothesis was confirmed in the current study, which showed that the children with OSAS had decreased upper airway dynamic responses during sleep compared with controls.

An alternative explanation for the lack of response to $\mathrm{CO}_{2}$ in the OSAS group could be that the children's upper airway was already maximally activated by negative pressure, and, therefore, hypercapnia could not elicit a further response. This theory is negated by the awake $\mathrm{P}_{\text {crit }}$ measurements. The airway of the children with OSAS resisted collapse during wakefulness, despite the application of the maximum $-20 \mathrm{~cm} \mathrm{H}_{2} \mathrm{O}$ of negative pressure. This indicates that the airway neuromotor response is greater during wakefulness than during sleep, even when multiple stimuli are applied during sleep.

\section{EFFECT OF T\&A}

Patients with OSAS were reevaluated $2-3$ mo postoperatively. This time period should be sufficient to evaluate postoperative changes. Polysomnography normalizes $6 \mathrm{wk}$ after T\&A (1); in fact, some studies suggest that it normalizes within several days $(37,38)$. Unfortunately, not all patients agreed to return for the rigorous follow-up experiments. However, the patients that were restudied were representative of the group. 
Clearly, further studies with a larger sample size would be beneficial. Nevertheless, we noted several trends in postoperative PFR responses that may have been significant with a larger sample size.

After T\&A, OSAS resolved in all patients except for one obese child. This clinical improvement was associated with a modest improvement in the intermittent $\mathrm{P}_{\text {crit }}$, reflecting the postoperative structural changes. Nevertheless, the intermittent $\mathrm{P}_{\text {crit }}$ remained less negative than in controls. This suggests ongoing structural differences between the two groups, such as a narrower upper airway in the OSAS group. This is consistent with studies in adults showing that patients with OSAS have narrower upper airways than controls (32).

The magnitude of change in the intermittent $\mathrm{P}_{\text {crit }}$ postoperatively was not sufficient to account for the normalization of the upper airway after surgery. An unanticipated finding, however, was the large change in the gradual $\mathrm{P}_{\text {crit }}$. Potential explanations for this include structural causes, neuromotor causes, and the effect of neuromechanical interaction.

\section{Structural causes}

It is possible that postoperative scarring resulted in a stiffening of the upper airway. However, the fact that the PFR changed only minimally in the patient in whom OSAS persisted, and that postoperative PFR changes were more marked using the gradual technique than the intermittent technique, goes against this. Furthermore, it has previously been shown that $P_{\text {crit }}$ falls to the same degree after successful treatment of adult OSAS by either surgical (uvulopalatopharyngoplasty) or medical (weight loss) means $(25,26)$. This suggests that the upper airway surgery per se did not affect $\mathrm{P}_{\text {crit }}$.

\section{Neuromotor causes}

Upper airway neuromotor responses may be diminished in children with OSAS preoperatively secondary to chronic upper airway obstruction, and may thus improve postoperatively. This may be due to habituation to chronic, sleep-related hypoxemia and hypercapnia, or to a decrease in the ventilatory drive secondary to sleep disruption. Alternatively, it may be due to direct vibrational damage of the upper airway nerves (39) due to chronic snoring (40). The neuromotor theory is supported by the literature. Previous studies have shown normalization of arousal responses to hypercapnia following T\&A in children (35). In addition, adults with OSAS have an improvement in the hypercapnic ventilatory drive following tracheostomy (41), and have improvement in upper airway sensation following CPAP administration (42).

\section{Neuromechanical interaction}

The increased collapsibility of the upper airway preoperatively may have been secondary to upper airway muscle fatigue, as a result of the upper airway muscles working against an increased load every night. This theory would be consistent with data from adults, showing that upper airway muscles work near their maximal range during wakefulness in patients with OSAS (43); in children, our data suggest that this increased muscle work continues during sleep. Alternatively, the structural load of the tonsils and adenoids could cause the upper airway muscles to work at a mechanical disadvantage. This would improve postoperatively with unloading of the upper airway.

\section{METHODOLOGIC LIMITATIONS}

It is important to note that during the intermittent runs the children with OSAS were studied using a higher holding pressure than the controls, although $\mathrm{P}_{\mathrm{N}}$ was decreased to subatmospheric levels in all but one of the OSAS subjects. The higher holding pressure could have resulted in more depression of the upper airway muscles in the OSAS group than in the controls. However, the fact that the OSAS group also had a decreased response to hypercapnia suggests that this was unlikely to have been the only reason for the lack of change between the gradual and the intermittent conditions, especially considering that upper airway receptors for negative pressure and $\mathrm{CO}_{2}$ are thought to be the same (44).

The control children in this study were older than the children with OSAS. It is also possible that some of the older children may have entered puberty. However, it is unlikely that this age difference affected the results, as all subjects were school-aged children, and there was no correlation between age and $\mathrm{P}_{\text {crit }}$ or slope. Furthermore, as upper airway collapsibility increases with age (6), if age were a factor it would be expected that the opposite effect would have been seen, i.e. that the OSAS group, who were younger, would have a greater response than the controls.

In our studies, we have used an arbitrary $\mathrm{P}_{\text {crit }}$ cutoff of -25 $\mathrm{cm} \mathrm{H}_{2} \mathrm{O}$ in those subjects in whom the slope of the PFR was very flat (9). This was necessary to allow us to perform statistical comparisons. However, this technique results in an underestimation of differences between groups. Nevertheless, it is clear from visualization of Figures 3 and 5 (performed without the cutoff) that $\mathrm{P}_{\text {crit }}$ differences between the groups were large.

\section{CONCLUSION}

This study has shown that children with OSAS lack upper airway neuromotor responses to negative pressure and hypercapnia during sleep. We speculate that this is secondary to chronic respiratory abnormalities during sleep. Upper airway responses improved after T\&A but did not reach normal levels, despite normalization of polysomnographic results. This suggests that, although T\&A is clearly beneficial in resolving clinical sleep-disordered breathing, subclinical abnormalities in upper airway function persist. Theoretically, this could put patients at risk for a recurrence of OSAS in later life. Further long-term studies evaluating upper airway function are needed.

Acknowledgments. The authors thank Peter Hill for supplying modified CPAP equipment to provide subatmospheric pressure. We also thank the children and their families for their enthusiastic participation in this study. 


\section{REFERENCES}

1. Suen JS, Arnold JE, Brooks LJ 1995 Adenotonsillectomy for treatment of obstructive sleep apnea in children. Arch Otolaryngol Head Neck Surg 121:525-530

2. Arens R, McDonough JM, Costarino AT, Mahboubi S, Tayag-Kier CE, Maislin G, Schwab RJ, Pack AI 2001 Magnetic resonance imaging of the upper airway structure of children with obstructive sleep apnea syndrome. Am J Respir Crit Care Med 164:698-703

3. Guilleminault C, Partinen M, Praud JP, Quera-Salva MA, Powell N, Riley R 1989 Morphometric facial changes and obstructive sleep apnea in adolescents. J Pediatr 114:997-999

4. Tasker C, Crosby JH, Stradling JR 2002 Evidence for persistence of upper airway narrowing during sleep, 12 years after adenotonsillectomy. Arch Dis Child 86:34-37

5. van Lunteren E, Strohl KP 1988 Striated respiratory muscles of the upper airways. In: Mathew OP, Sant'Ambrogio G (eds) Respiratory Function of the Upper Airway. Marcel Dekker, New York, pp 87-123

6. Marcus CL, Lutz J, Hamer A, Smith PL, Schwartz A 1999 Developmental changes in response to subatmospheric pressure loading of the upper airway. J Appl Physiol $87: 626-633$

7. Weiner D, Mitra J, Salamone J, Cherniack NS 1982 Effect of chemical stimuli on nerves supplying upper airway muscles. J Appl Physiol 52:530-536

8. Strohl KP, Redline S 1986 Nasal CPAP therapy, upper airway muscle activation, and obstructive sleep apnea. Am Rev Respir Dis 134:555-558

9. Marcus CL, Fernandes Do Prado LB, Lutz J, Katz ES, Black CA, Galster P, Carson KA 2004 Developmental changes in upper airway dynamics. J Appl Physiol 97:98-108

10. Schwartz AR, O'Donnell CP, Baron J, Schubert N, Alam D, Samadi SD, Smith PL 1998 The hypotonic upper airway in obstructive sleep apnea: a role of structures and neuro-muscular activity. Am J Respir Crit Care Med 157:1051-1057

11. Launois SH, Feroah TR, Campbell WN, Issa FG, Morrison D, Whitelaw WA, Isono S, Remmers JE 1993 Site of pharyngeal narrowing predicts outcome of surgery for obstructive sleep apnea. Am Rev Respir Dis 147:182-189

12. Rosner B, Prineas R, Loggie J, Daniels SR 1998 Percentiles for body mass index in U.S. children 5 to 17 years of age. J Pediatr 132:211-222

13. Rechtschaffen A, Kales A 1968 A Manual of Standardized Terminology: Techniques and Scoring Systems for Sleep Stages of Human Subjects. NINDB Neurological Information Network (U.S.), Bethesda, MD

14. Sleep Disorders Atlas Task Force 1992 EEG arousals: scoring rules and examples: a preliminary report from the Sleep Disorders Atlas Task Force of the American Sleep Disorders Association. Sleep 15:173-184

15. American Academy of Sleep Medicine Task Force 1999 Sleep-related breathing disorders in adults: recommendations for syndrome definition and measurement techniques in clinical research. The Report of an American Academy of Sleep Medicine Task Force. Sleep 22:667-689

16. American Thoracic Society 1996 Standards and indications for cardiopulmonary sleep studies in children. Am J Respir Crit Care Med 153:866-878

17. Marcus CL, Omlin KJ, Basinki DJ, Bailey SL, Rachal AB, Von Pechmann WS, Keens TG, Ward SL 1992 Normal polysomnographic values for children and adolescents. Am Rev Respir Dis 146:1235-1239

18. Boudewyns A, Punjabi N, Van de Heyning PH, De Backer WA, O'Donnell CP, Schneider H, Smith PL, Schwartz AR 2000 Abbreviated method for assessing upper airway function in obstructive sleep apnea. Chest 118:1031-1041

19. Goh DY, Galster P, Marcus CL 2000 Sleep architecture and respiratory disturbances in children with obstructive sleep apnea. Am J Respir Crit Care Med 162:682-686

20. Condos R, Norman RG, Krishnasamy I, Peduzzi N, Goldring RM, Rapoport DM 1994 Flow limitation as a noninvasive assessment of residual upper-airway resistance during continuous positive airway pressure therapy of obstructive sleep apnea. Am J Respir Crit Care Med 150:475-480

21. Marcus CL, McColley SA, Carroll JL, Loughlin GM, Smith PL, Schwartz AR 1994 Upper airway collapsibility in children with obstructive sleep apnea syndrome. J Appl Physiol 77:918-924
22. Chervin RD, Ruzicka DL, Wiebelhaus JL, Hegeman GL 3rd, Marriott DJ, Marcus CL, Giordani BJ, Weatherly RA, Dillon JE 2003 Tolerance of esophageal pressure monitoring during polysomnography in children. Sleep 26:1022-1026

23. Katz ES, White DP 2003 Genioglossus activity in children with obstructive sleep apnea during wakefulness and sleep onset. Am J Respir Crit Care Med 168:664-670

24. Smith PL, Wise RA, Gold AR, Schwartz AR, Permutt S 1988 Upper airway pressure-flow relationships in obstructive sleep apnea. J Appl Physiol 64:789-795

25. Schwartz AR, Gold AR, Schubert N, Stryzak A, Wise RA, Permutt S, Smith PL 1991 Effect of weight loss on upper airway collapsibility in obstructive sleep apnea. Am Rev Respir Dis 144:494-498

26. Schwartz AR, Schubert N, Rothman W, Godley F, Marsh B, Eisele D, Nadeau J, Permutt L, Gleadhill I, Smith PL 1992 Effect of uvulopalatopharyngoplasty on upper airway collapsibility in obstructive sleep apnea. Am Rev Respir Dis 145:527-532

27. Gleadhill IC, Schwartz AR, Schubert N, Wise RA, Permutt S, Smith PL 1991 Upper airway collapsibility in snorers and in patients with obstructive hypopnea and apnea. Am Rev Respir Dis 143:1300-1303

28. Gold AR, Marcus CL, Dipalo F, Gold MS 2002 Upper airway collapsibility during sleep in upper airway resistance syndrome. Chest 121:1531-1540

29. Isono S, Shimada A, Utsugi M, Konno A, Nishino T 1998 Comparison of static mechanical properties of the passive pharynx between normal children and children with sleep-disordered breathing. Am J Respir Crit Care Med 157:1204-1212

30. Carlo WA, Miller MJ, Martin RJ 1985 Differential response of respiratory muscles to airway occlusion in infants. J Appl Physiol 59:847-852

31. Gauda EB, Miller MJ, Carlo WA, Difiore JM, Johnsen DC, Martin RJ 1987 Genioglossus response to airway occlusion in apneic versus nonapneic infants. Pediatr Res 22:683-687

32. Schwab RJ, Gefter WB, Hoffman EA, Gupta KB, Pack AI 1993 Dynamic upper airway imaging during awake respiration in normal subjects and patients with sleep disordered breathing. Am Rev Respir Dis 148:1385-1400

33. Philip-Joet F, Marc I, Series F 1996 Effects of genioglossal response to negative airway pressure on upper airway collapsibility during sleep. J Appl Physiol 80:1466-1474

34. Hudgel DW, Hendricks C, Dadley A 1988 Alteration in obstructive apnea pattern induced by changes in oxygen- and carbon-dioxide-inspired concentrations. Am Rev Respir Dis 138:16-19

35. Marcus CL, Lutz J, Carroll JL, Bamford O 1998 Arousal and ventilatory responses during sleep in children with obstructive sleep apnea. J Appl Physiol 84:1926-1936

36. Marcus CL, Gozal D, Arens R, Basinski DJ, Omlin KJ, Keens TG, Ward SL 1994 Ventilatory responses during wakefulness in children with obstructive sleep apnea. Am J Respir Crit Care Med 149:715-721

37. Helfaer MA, McColley SA, Pyzik PL, Tunkel DE, Nichols DG, Baroody FM, April MM, Maxwell LG, Loughlin GM 1996 Polysomnography after adenotonsillectomy in mild pediatric obstructive sleep apnea. Crit Care Med 24:1323-1327

38. Kudoh F, Sanai A 1996 Effect of tonsillectomy and adenoidectomy on obese children with sleep-associated breathing disorders. Acta Otolaryngol Suppl 523:216-218

39. Friberg D, Ansved T, Borg K, Carlsson-Nordlander B, Larsson H, Svanborg E 1998 Histological indications of a progressive snorers disease in an upper airway muscle. Am J Respir Crit Care Med 157:586-593

40. Svanborg E 2001 Upper airway nerve lesions in obstructive sleep apnea. Am J Respir Crit Care Med 164:187-189

41. Guilleminault C, Cummiskey J 1982 Progressive improvement of apnea index and ventilatory response to $\mathrm{CO}_{2}$ after tracheostomy in obstructive sleep apnea syndrome. Am Rev Respir Dis 126:14-20

42. Kimoff RJ, Sforza E, Champagne V, Ofiara L, Gendron D 2001 Upper airway sensation in snoring and obstructive sleep apnea. Am J Respir Crit Care Med 164:250-255

43. Mezzanotte WS, Tangel DJ, White DP 1992 Waking genioglossal electromyogram in sleep apnea patients versus normal controls (a neuromuscular compensatory mechanism). J Clin Invest 89:1571-1579

44. Anderson JW, Sant'Ambrogio FB, Orani GP, Sant'Ambrogio G, Mathew OP 1990 Carbon dioxide-responsive laryngeal receptors in the dog. Respir Physiol $82: 217-226$ 